\title{
Ethanolic Extract of Moringa oleifera L. Increases Sensitivity of WiDr Colon Cancer Cell Line Towards 5-Fluorouracil
}

\author{
Kholid Alfan Nur, Herwandhani Putri, Fany Mutia Cahyani, Aulia Katarina, \\ Ratna Asmah Susidarti, Edy Meiyanto* \\ Cancer Chemoprevention Research Center, Faculty of Pharmacy \\ Universitas Gadjah Mada \\ Jalan Sekip Utara Sleman Yogyakarta 555281 (Telp. 02746492662 Fax. 543120)
}

\begin{abstract}
For more than four decades, combination chemotherapy (co-chemotherapy) has been employed as a means to increase the effectiveness of chemotherapy regiments. The aim of our research is to investigate the activity of Moringa oleifera L. (tanaman kelor) ethanolic extract (MEE) as a co-chemotherapy agent with 5-fluorouracil (5-FU) on WiDr colon cancer cell line. Evaluation of MEE potency as a co-chemotherapy agent with 5-FU was based on cytotoxic activity based on percent cell viability via MTT assay, and based on apoptosis observation via the double staining method using acrydin orange-ethidium bromide ( $A E$ ) as the staining reagent.Cytotoxicity evaluation of single treatment using concentrations of 5, 20, 50, 100,125, and $250 \mu \mathrm{g} / \mathrm{ml}$ of MEE reduced cell viability 24 hours post-treatment. 5, 50, and $250 \mu \mathrm{g} / \mathrm{ml}$ of MEE was chosen as the combination concentrations with $1000 \mu \mathrm{M} 5$-FU. MTT assay 24 hours and 48 hours post-combination treatment showed significant cell viability reduction in comparison to those of single treatments. Apoptosis observation using the double staining method shows the presence of apoptotic cells 48 hours post combination treatment. MEE is a potential co-chemotherapy agent by increasing the sensitivity of WiDr colon cancer cell line towards 5-FU.
\end{abstract}

Keywords: co-chemotherapy, 5-fluorouracil, Moringa oleifera L., colon cancer

\section{INTRODUCTION}

Of the many cancer therapies, chemotherapy remains the conventional and main method to prescribe. Chemotherapy involves the use of synthetic chemical agents to suppress cancer cell proliferation or to destroy cancer cells. 5Fluorouracil (5-FU) is currently dubbed as the main chemotherapy agent for the treatment of colon cancer. However, 5-FU is also notorious for its adverse side effects and is prone to cause resistance on cancer cells (Kodach et al, 2006). To solve this problem, combination chemotherapy (co-chemotherapy) is a viable option to delve in to.

Co-chemotherapy is an effort to reduce the side effects of chemotherapy by introducing additional anticancer agent(s) within the therapy regiment(s). When the interaction between the two agents is synergistic, co-chemotherapy can increase the potency of the chemotherapy agent to cancer cell proliferation (Brenner, 2002). Moringa oleifera L. is a plant known to have anticancer activity.

Many research have reported the anticancer activity of Moringa oleifera $\mathrm{L}$. This plant contains a unique combination of molecules called isothiocyanates and glucocynolates. It has been reported that isothiocyanates have chemopreventive properties by modifying the metabolic processes of carcinogenesis through inhibition of phase 1 metabolic enzymes and/or induction of phase 2 metabolic enzymes (Hetch, 2009). Benzyl isothiocyanate, an analogue of isothiocyanate, has shown apoptotic activity on ovarian cancer and $\mathrm{G}_{2} / \mathrm{M}$ cell cycle arrest on pancreatic cancer cells (Srivastava and Singh, 2004).

\footnotetext{
*Corresponding author e-mail: meiyan_e@ugm.ac.id
} 
Bharali et al (2003) have also reported ethanolic extracts of Moringa oleifera L. is a potential chemopreventive agent in suppressing carcinogenesis due to toxic chemicals exposure. Based on those research, it can be hypothesized that ethanolic extracts of Moringa oleifera $\mathrm{L}$. is a potential co-chemotherapy agent with 5-FU

\section{MATERIALS AND METHOD}

\section{Plant sample and extract preparation- Moringa oleifera $\mathbf{L}$.}

Was obtained from nature in the Yogyakarta area, which was then officially determined by the Biological Pharmaceutics Department of the Faculty of Pharmacy, Universitas Gadjah Mada. The extract was then prepared by using 95\% ethanol as the solvent for maceration. The macerate was then strained and a dilute extract was obtained. The extract was concentrated using a rotary evaporator continued with freeze drying to further eliminate traces of ethanol. The concentrated extract was then dissolved in DMSO (Sigma) for treatment.

\section{WiDr cell preparation}

WiDr colon cancer cell line used in this study was obtained from the collection of Cancer Chemoprevention Research Center of the Faculty of Pharmacy Universitas Gadjah Mada. WiDr was cultured in RPMI growth medium (Gibco) containing 10\% v/v fetal bovine serum (Gibco), $1 \% \mathrm{v} / \mathrm{v}$ penicillin-streptomycin (Gibco), and $0,05 \% \mathrm{v} / \mathrm{v}$ fungizone (Gibco). Cell was cultivated from the culture dish using tripsin-EDTA 0,25\% v/v (Gibco).

\section{Cytotoxicity assay procedure}

Cultivated cells were transferred into 96well plates (Iwaki) then incubated for until confluent. Once the cells are confluent, treatment was conducted in accordance to the pre-calculated concentrations. MTT reagent was added 24 hours or 48 hours post-treatment (depending on the experiment), then SDS $10 \% \mathrm{v} / \mathrm{v}$ in $\mathrm{HCl}$ was added 4 hours later. Following an overnight incubation period, the cell's absorbance was read using microplate reader.

\section{Apoptosis detection procedure}

Cover slips (Iwaki) were placed in 24-well plate (Iwaki) then cells are transferred on to them, then incubated until confluent. The confluent cells are then treated with the selected dosage according to the co-chemotherapy MTT results. Once incubated for 48 hours post-treatment, the cover slips are removed from the wells and stained with $10 \mu \mathrm{L}$ of Acrydin orange-Ethidium bromide (AE) to stain the cells. The stained cells are observed and recorded under fluorescent microscope.

\section{RESULTS}

\section{Cytotoxicity assay of single MEE treatment} and 5-FU - MEE combination treatment

The MTT assay results show that MEE increases WiDr cell's sensitivity towards 5-FU. MTT assay of MEE as a single agent shows reduced cell viability due to treatment (Figure 1). From this result, concentrations of 5, 50, and 250 $\mu \mathrm{g} / \mathrm{ml}$ MEE was chosen as the combination concentrations which represents the whole range of data. Co-chemotherapy treatment using 1000 $\mu \mathrm{M} 5$-FU with 5, 50, and $250 \mu \mathrm{g} / \mathrm{ml}$ MEE shows further cell viability reduction (Figure 2). Continued co-chemotherapy treatment for 48 hours gave the best results (Figure 2). Percent cell viability of $50 \%$ ( $\mathrm{IC}_{50}$ value) was obtained for concentration of $1000 \mu \mathrm{M} 5$-FU with $50 \mu \mathrm{g} / \mathrm{ml}$ MEE. 


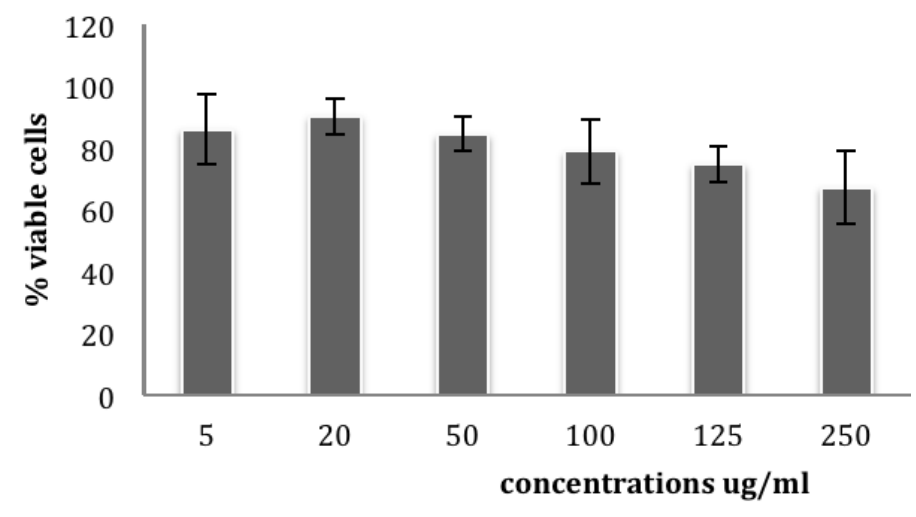

Figure I. Cytotoxicity evaluation of single MEE treatment on WiDr cells. Assay was conducted by incubating WiDr cell in 96 -well plate for 24 hours to normalize. Treatment series of $5-250 \mu \mathrm{g} / \mathrm{ml}$ was administered followed by further incubation for $\mathbf{2 4}$ hours as described in the methodology. Cell viability data was obtained thourgh convertion of absorbanse from formazan cyrstal formation due MTT treatment, as described in the methodology. Viabilty profile is presented from the mean \pm standard error (SE) from 3 experiments. The treatment of MEE on WiDr resulted in reduced cell viability.

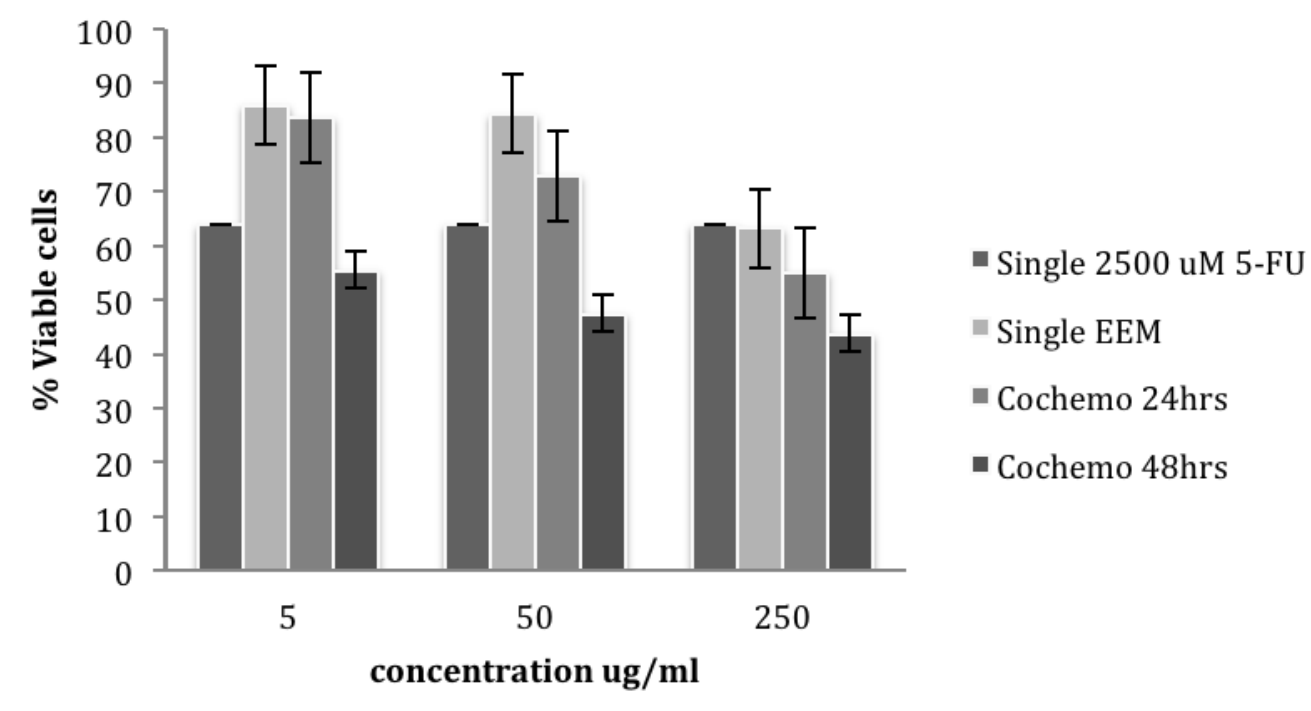

Figure 2. Cytotoxicity evaluation of combination treatment post 24 hours and $\mathbf{4 8}$ hours treatment. Assay was conducted by incubating WiDr cell in 96-well plate for 24 hours to normalize. Combination treatment series of 5, 50, $250 \mu \mathrm{g} / \mathrm{ml}$ MEE with $1000 \mu \mathrm{M}$ was administered followed by further incubation for 24 hours or 48 hours as described in the methodology. Cell viability data was obtained thourgh convertion of absorbanse from formazan cyrstals formation due MTT treatment, as described in the methodology. As comparison, single 2500uM 5-FU and EEM data is also presented. Viabilty profile is presented from the mean \pm standard error (SE) from 3 experiments. The combination treatment of MEE - 5-FU for 24 hours on WiDr resulted in greater cell viability reduction compared to single treatments. Further cell viability reduction was observed post 48 hours treatment.

These cell deaths were most likely due to apoptosis. To ascertain this postulation, we 
continued further with our investigation and conducted apoptosis detection assay using the double staining method.

\section{Detection of apoptotic cells using double staining method}

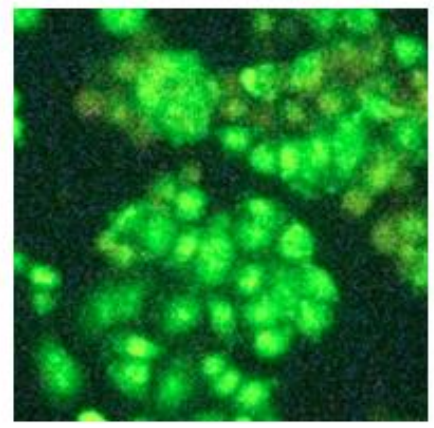

A

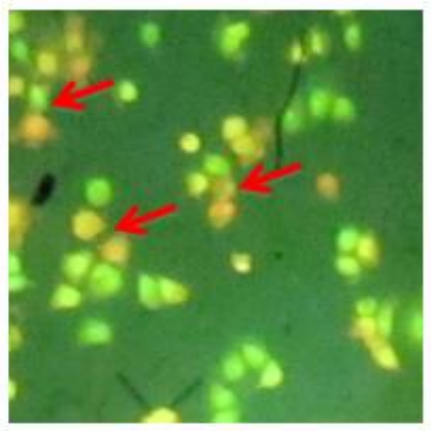

c
Results of apoptosis detection show that reduction of cell viability post treatment was due to apoptosis. In the control (Fig 3(A)), only green fluorescent cells are present indicating the absence of apoptotic cells. It is in the treatment cells that the occurrence of apoptosis was observed. At combination concentration of $1000 \mathrm{uM} 5$-FU with $50 \mathrm{ug} / \mathrm{ml} \mathrm{MEE}$, orange fluorescent cells develop (Figure 3B-3D).
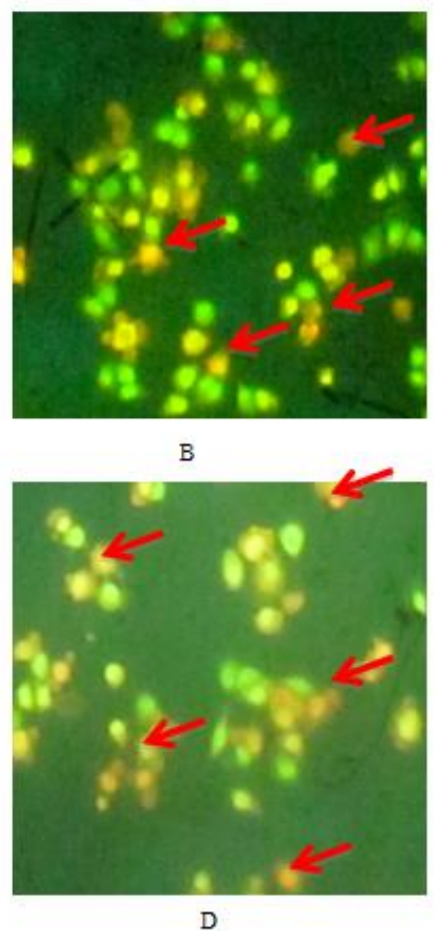

Figure 3. (A) control (B) - (D) results of double staining following 48 hours post co-chemotherapy treatment concentration of $1000 \mu \mathrm{M}$ 5-FU with $50 \mu \mathrm{g} / \mathrm{ml}$ MEE. Cells were seeded on cover slips in 24-well plates and treated with combination of $1000 \mu \mathrm{M} 5-\mathrm{FU}$ with $50 \mu \mathrm{g} / \mathrm{ml}$ MEE. After 48 hours of incubation each well was washed with PBS, cover slips removed, then treated with ethidium bromide - acrydin orange fluorescent dye. Living cells emit green fluorescence while apoptotic cells emit orange fluorescence (arrowed).

\section{DISCUSSION}

Our hypothesis, that MEE has a potential as a co-chemotherapy agent with 5 -FU in colon cancer treatment, was confirmed by the research findings. MTT assay of single MEE treatment show reduction of cell viability. Further and more significant cell viability reduction was observed on the combination treatment cell viability profile.

The mechanism of action of 5-FU - MEE combination is due to enhancement of cancer cell cytotoxicity. As reported by De Angelis et. al. (2006) 5-FU damages the DNA double strand and induce apoptosis of colon cancer cells, which is mediated by the p53 protein. Benzyl isothiocyanate (BITC) and phenethyl isothiocyanate (PEITC), the principle antitumoregenesis compounds in Moringa oleifera L., have been previously reported to induce apoptosis. BITC up-regulate the $\mathrm{p} 21$ protein, resulting in cell apoptosis (Zhang, R., et. al., 2009). PEITC causes cell apoptosis by down-regulating Bcl-2/XIAP and through the mitochondrial pathway (Lee, J.W., and Cho, M.K., 2008). Our research findings are in accordance to these previously reported studies.

Our data showed that cell viability reduction is apparently dosage dependent. As shown in Figure 1, each increase in treatment concentration 
correlates with reduction in cell viability. An even more significant cell viability reduction profile was observed from co-chemotherapy treatment (Figure 2). Results show that combination treatment enhances the effectiveness of 5-FU in reducing cell viability. The combination treatment post 48 hours is particularly noteworthy. Even though the treatment dosage (1000 uM 5-FU with $50 \mathrm{ug} / \mathrm{ml}$ ) was much lower than the single 5-FU cytotoxicity profile of $2500 \mathrm{uM}$ (resulting in $63.8 \%$ viable cells), it was able to result in percent cell viability of $47.8 \%$. To further reaffirm that the reduced cell viability was due to apoptosis, we conducted the double staining apoptosis assay using ethidium bromide - acrydin orange. As shown in figure 3 , treatment of $1000 \mathrm{uM} \mathrm{5-FU}$ with $50 \mathrm{ug} / \mathrm{ml}$ resulted in the appearance of apoptotic bodies.

To explore the underlying cytotoxicity and apoptosis induction mechanism, further research is needed. Flow cytometric analysis is needed to determine the effect on cell cycle progression. Western Blotting should also be conducted to ascertain which proteins are involved.

\section{CONCLUSION}

The anti-tumoregenesis activity of 5-FU is enhanced through combination with MEE through increased cytotoxicity and apoptosis induction. MEE has potential to become a co-chemotherapy agent with 5-FU.

\section{REFERENCES}

Bharali, R., Tabassum, J. and Azad, M.R.H., 2003, Chemomodulatory effect of Moringa Oleifera L. on hepatic carcinogen metabolising enzyme, antioxidant parameters, and skin papillomagenesis in mice, Asia Pacific Journal of Cancer Prevention, 4, I3I-139.
Brenner, D.E., 2002, New paradigms in oncological therapeutics: redefining combination chemotherapy, Annals of Oncology, 13, 1697-1698.

De Angelis, P.M., Svendsurd, D.H., Kravik, K.L. and Stokke, T., 2006, Cellular response to fluorouracil (5-FU) in FU-resistant colon cancer cell lines during treatment and recovery, Mol. Cancer, 5, 20.

Hetch, S.S., 2009, Chemoprevention of cancer by isothicyanates, modifiers of carcinogen metabolism, Journal of Nutrition, I 29, 768s-774s.

Kodach, L.L., Bos, C.L., Duran, N., Peppelenbosch, M.P., Ferreira, C.V. and Hardwick, J.C.H., 2006, Violacein synergistically increases 5-fluorouracil cytotoxicity, induces apoptosis, and inhibits Aktmediated signal transduction in human colorectal cancer cells, Carcinogenesis, 27(3), 508-5I6.

Lee, J.W. and Cho, M.K., 2008, Phenethyl Isothiocyanates induced apoptosis via down regulation of $\mathrm{Bcl}-2 / \mathrm{XIAP}$ and triggering the mitochondrial pathway in MCF-7 cells, Arch. Pharm. Res., 3I(I2), 1604-1612.

Srivastava, S.K. and Singh, S.V., 2004, Cell cycle arrest, apoptosis induction and inhibition of nuclear factor kappa B activation in antiproliverative activity of benzyl isothiocyanate against human pancreatic cancer cells, Carcinogenesis, 25(9), I70I-I709.

Zhang, R., Loganathan, S., Humphreys, I., and Srivastava, S., 2009, Benzyl isothiocyanate-induced DNA damage causes G2/M cell cycle arrest and apoptosis in human pancreatic cancer cells, Journals of Nutrition, 136, 27282734. 